\title{
OPPORTUNITIES AND CHALLENGES FOR STRUCTURAL HEALTH MONITORING OF RADIOACTIVE WASTE SYSTEMS AND STRUCTURES
}

\author{
Victor Giurgiutiu, PhD \\ University of South Carolina \\ Columbia, SC 29208, USA \\ victorg@sc.edu
}

\author{
Adrián E. Méndez Torres, PhD \\ Savannah River National Laboratory \\ Aiken, SC 29808, USA \\ Adrian.Mendez-Torres@srnl.doe.gov
}

\begin{abstract}
Radioactive waste systems and structures (RWSS) are safety-critical facilities in need of monitoring over prolonged periods of time. Structural health monitoring (SHM) is an emerging technology that aims at monitoring the state of a structure through the use of networks of permanently mounted sensors. SHM technologies have been developed primarily within the aerospace and civil engineering communities. This paper addresses the issue of transitioning the SHM concept to the monitoring of RWSS and evaluates the opportunities and challenges associated with this process. Guided wave SHM technologies utilizing structurally-mounted piezoelectric wafer active sensors (PWAS) have a wide range of applications based on both propagating-wave and standing-wave methodologies. Hence, opportunities exist for transitioning these SHM technologies into RWSS monitoring. However, there exist certain special operational conditions specific to RWSS such as: radiation field, caustic environments, marine environments, and chemical, mechanical and thermal stressors. In order to address the high discharge of used nuclear fuel (UNF) and the limited space in the storage pools the U.S. the Department of Energy (DOE) has adopted a "Strategy for the Management and Disposal of Used Nuclear Fuel and High-Level Radioactive Waste" (January 2013). This strategy endorses the key principles that underpin the Blue Ribbon Commission's on America's Nuclear Future recommendations to develop a sustainable program for deploying an integrated system capable of transporting, storing, and disposing of UNF and high-level radioactive waste from civilian nuclear power generation, defense, national security, and other activities. This will require research to develop monitoring, diagnosis, and prognosis tools that can aid to establish a strong technical basis for extended storage and transportation of UNF. Monitoring of such structures is critical for assuring the safety and security of the nation's spent nuclear fuel until a national policy for closure of the nuclear fuel cycle is defined and implemented. In addition,
\end{abstract}

such tools can provide invaluable and timely information for verification of the predicted mechanical performance of RWSS (e.g. concrete or steel barriers) during off-normal occurrence and accident events such as the tsunami and earthquake event that affected Fukushima Daiichi nuclear power plant. The ability to verify the conditions, health, and degradation behavior of RWSS over time by applying nondestructive testing (NDT) as well as development of nondestructive evaluation (NDE) tools for new degradation processes will become challenging. The paper discusses some of the challenges associated to verification and diagnosis for RWSS and identifies SHM technologies which are more readily available for transitioning into RWSS applications. Fundamental research objectives that should be considered for the transition of SHM technologies (e.g., radiation hardened piezoelectric materials) for RWSS applications are discussed. The paper ends with summary, conclusions, and suggestions for further work.

\section{INTRODUCTION}

Nuclear power plants (NPP) and radioactive waste systems and structures (RWSS) are safety-critical facilities in need of monitoring over prolonged periods of time. Monitoring these aging structures with minimum human intervention is of paramount importance. For example, the U.S. Nuclear Regulatory Commission (NRC) has provided in July 12, 2011 the recommendation on how to enhance "spent fuel makeup capability and instrumentation for the spent fuel pool" [1]. This includes the recommendation to provide sufficient safetyrelated instrumentation (able to withstand the design-based natural phenomena) to monitor from a control room the key parameters of the spent fuel pool (i.e., temperature, radiation level).

One of the key aspects of improving the reliability, sustaining the safety, and extending the life of current RWSS is to develop technologies that can better diagnose the health of nuclear related systems and structures such as RWSS. In order 
to achieve this objective, NDE material condition monitoring and SHM systems must be integrated to quantify the "state of health" of the systems and structures employed for radioactive waste systems such as high level waste (HLW) tanks and nuclear spent fuel interim storage systems (i.e. spent fuel ponds and dry cask storage systems).

One possible way to assess the current condition of structures, and, more importantly, to predict RWSS residual safe operating life is to develop new sensing techniques that monitor the integrity of RWSS components. SHM can be an essential tool to monitor important to safety (ITS) structures and assess the health of structures after an off-normal occurrence or natural accident event. This need has become evident in the U.S. in the defense waste RWSS (HLW tanks) at Hanford, WA and in Japan after the tsunami and earthquake that affected the Fukushima Daiichi nuclear plant and spent fuel ponds[2]. Both events have resulted in the release of radioactive material to the environment. By implementing "embedded" nondestructive sensors such as piezoelectric wafer active sensors (PWAS), SHM can enhance the inspectability of RWSS. This will allow real-time assessment of the structural conditions and prediction of service life with greater reliability.

\section{STRUCTURAL HEALTH MONITORING (SHM)}

Structural health monitoring (SHM) assesses the state of structural health and, through appropriate data processing and interpretation, may predict the remaining life of the structure [3]. Structural health is a major concern of the engineering community and SHM is especially important for detection and monitoring of structure degradation such as crack growth under

Propagating Lamb waves

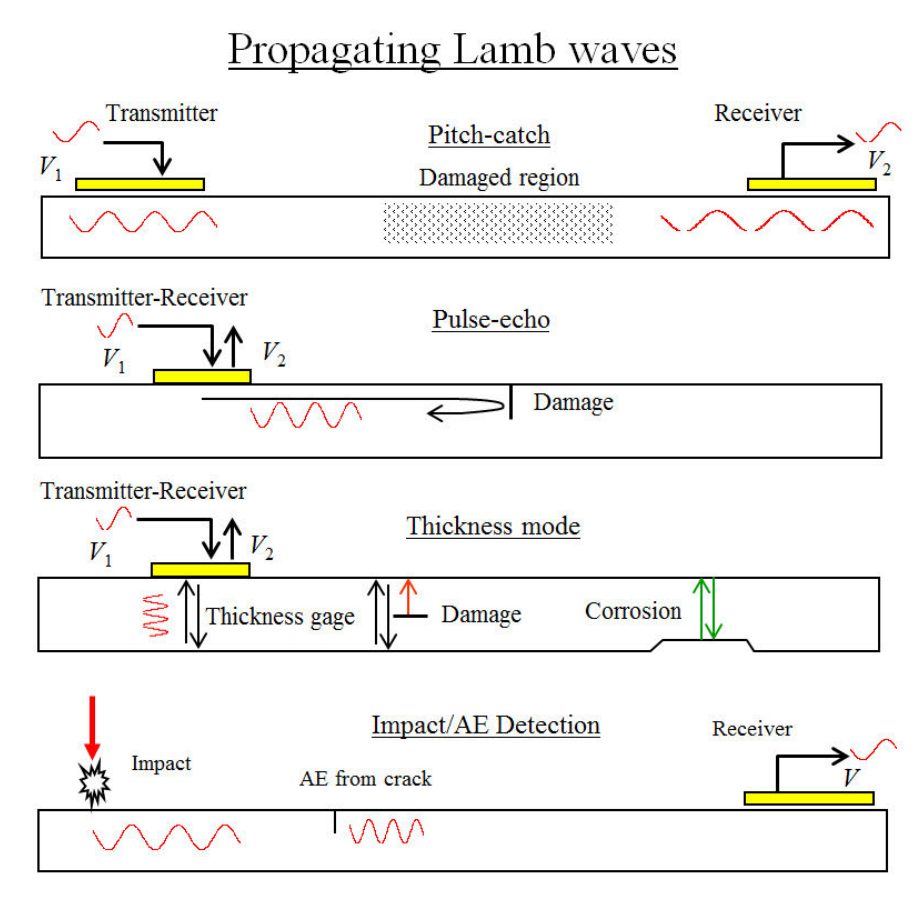

fatigue loading and/or due to environmental degradation conditions, such as corrosion due to marine environment. SHM methods can be passive or active: passive SHM infers the state of structural health from measuring various operational parameters. For example, one could monitor the flight parameters of an aircraft (airspeed, air turbulence, g-factors, vibration levels, stresses in critical locations, etc.) and then use the aircraft design algorithms to infer how much of aircraft's useful life has been used up and how much remains. Passive SHM is useful, but it does not directly address the crux of the problem, i.e., it does not directly examine if the structure has been damaged or not. Active SHM is concerned with directly assessing the state of structural health by detecting the presence and extent of structural damage. In this respect, the active SHM approach is similar to the approach taken by ultrasonic NDE, only that active SHM takes it one step further: active SHM uses damage detection sensors that can be permanently installed on the structure and its monitoring methods can provide on demand a structural health bulletin. The active SHM methods use smart sensors that can send and receive elastic waves in the structure. Thus, they can perform damage detection on demand.

\section{PIEZOELECTRIC WAFER ACTIVE SENSORS (PWAS)}

One type of smart sensor for active SHM is the piezoelectric wafer active sensor (PWAS). The PWAS transducers can be permanently attached to a structure and left in place during operation while still being small, inexpensive, unobtrusive, and reliable [4][5][6][7].

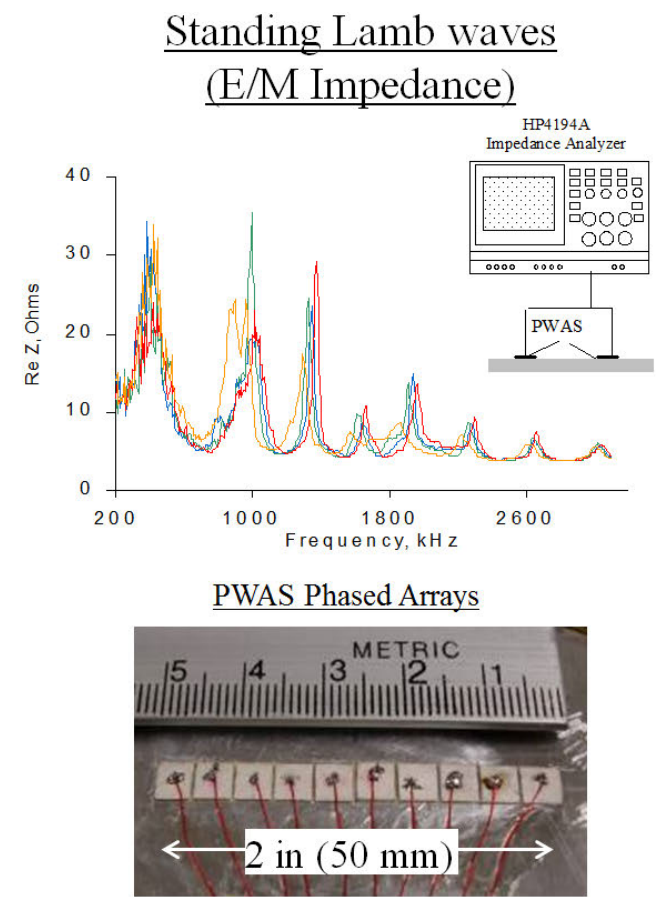

Figure 1 Use of piezoelectric wafer active sensors (PWAS) as traveling wave and standing wave transducers for damage detection in thin-wall structures [8] 
Piezoelectric wafer active sensors (PWAS) are two-way transducers [8] that couple the electrical and mechanical effects (mechanical strain $S_{i j}$, mechanical stress $T_{k l}$, electrical field $E_{k}$, and electrical displacement $D_{j}$ ) through the tensorial piezoelectric constitutive equations

$$
S_{i j}=s_{i j k l}^{E} T_{k l}+d_{k i j} E_{k}, \quad D_{j}=d_{j k l} T_{k l}+\varepsilon_{j k}^{T} E_{k}
$$

The tensor $s_{i j k l}^{E}$ is the mechanical compliance of the material measured at zero electric field ( $E=0), \varepsilon_{j k}^{T}$ is the dielectric permittivity measured at zero mechanical stress $(T=0)$, and $d_{k i j}$ represents the piezoelectric coupling effect. PWAS utilize the $d_{31}$ coupling between in-plane strains, $S_{1}, S_{2}$, and transverse electric field, $E_{3}$. By using Lamb waves in "thinwall" structures such as storage tanks, piping, and pressure vessels, one can detect structural anomaly, i.e., cracks, corrosions, delaminations, and other damage. A more thorough examination of PWAS transducers, their uses, their advantages, and their differences from conventional ultrasonic transducers is given in ref. [8].

PWAS transducers can serve several SHM purposes (Figure 1):

(a) high-bandwidth strain sensors

(b) high-bandwidth wave exciters and receivers

(c) resonators

(d) embedded modal sensors with the electromechanical (E/M) impedance method

By application types, PWAS transducers can be used for:

(i) active sensing of far-field damage using pulse-echo, pitch-catch, and phased-array methods,

(ii) active sensing of near-field damage using high-frequency
E/M impedance method and thickness-gage mode, and

(iii) passive sensing of damage-generating events through detection of low-velocity impacts and acoustic emission at the tip of advancing cracks.

PWAS transducers act as both transmitters and receivers of Lamb waves traveling in a plate. Transmission happens upon excitation with an electric signal, the PWAS generate Lamb waves into a thin-wall structure. The generated Lamb waves travel into the structure and are reflected or diffracted by the structural boundaries, discontinuities, and damage. The reflected or diffracted waves arrive back at the PWAS where they are transformed into electric signals. In spite of their small size, PWAS are able to replicate many of the functions performed by conventional ultrasonic probes.

\section{DAMAGE IMAGING WITH PWAS PHASED-ARRAYS}

The phased-array implementation of the PWAS array concept permits damage to be identified by scanning beams emitting from a central location just like aircraft targets are found in the sky by phased array radars. The embedded ultrasonic structural radar (EUSR) method, reported extensively in ref. [9], is a practical application of the PWAS phased array concept. The basic idea of the EUSR algorithm is to use a group of PWAS arranged in a particular pattern and manipulate the synthetic output beam at a particular direction by adjusting the delays between the firing of each element. Among the possible array configurations, the linear array obtained by arranging elements along a straight line presents is the simplest one, as illustrated in Figure 2a.
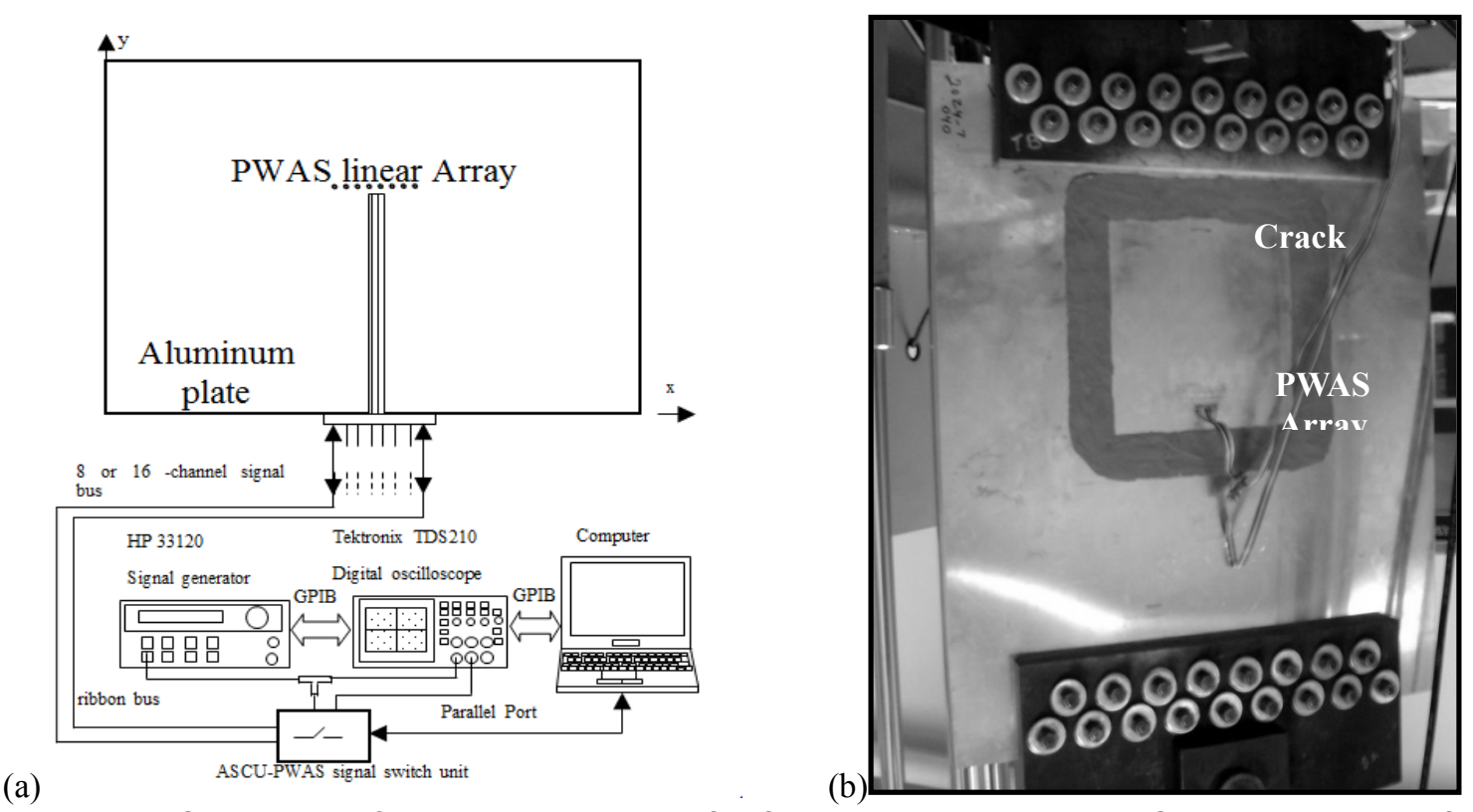

Figure 2 Schematic of experimental setup for fatigue testing with PWAS: (a) schematic of specimen \#2 showing the installation of the PWAS array and the location of the precrack; (b) instrumentation schematics [10] 
The phased-array concept was used on a 600 -mm by 700 $\mathrm{mm}$ panel of 1-mm 2024-T3 aluminum alloy instrumented with a 10-PWAS phased array placed at its center (Figure 2b) [10]. The instrumentation consisted of an HP 33120 signal generator, a TDS210 digital oscilloscope, an ASCU auto-switch unit, and a laptop computer (Figure 2a). Round-robin data collection was performed in the following way: a 3 -count $372 \mathrm{kHz}$ tone-burst excitation signal was synthesized in the function generator at a frequency corresponding to the optimum tuning of the PWAS with the S0 Lamb-wave mode in the plate.

The tone-burst signal is sent to one PWAS in the array, travels into the plate, and is reflected at the crack and later at the plate boundary. The reflected Lamb-waves packet is received back at all the elements of the PWAS array. The signals received at each PWAS in the array (including the transmitting PWAS) and collected by the DAQ device, i.e., the digital oscilloscope generate a column of 10 elemental signals in a 100 elementalsignals array. This procedure is repeated for all the PWAS [10].
The EUSR algorithm software processes the measured PWAS phased array data and produces an image of the scanning results. Figure $3 \mathrm{a}$ shows the EUSR front panel. The threshold value, the values $\delta$, and $\theta$ of the "dial angles" were controlled from the panel (Figure 3b). First, an approximate position of the crack edge is obtained with the azimuth dial. If the azimuth dial is turned to an angle where the synthetic beam find a target and gets a reflection, then the A-scan image will show a reflection echo as illustrated in Figure 3a. After a threshold value was chosen, the $\theta$ and $\delta$ angles were adjusted such that their rays touched the left and right tips (respectively) of the crack image reproduced in the EUSR GUI. The EUSR image was then used to obtain an estimation of the crack size.

To verify the PWAS phased array detection capability under operational loads, the specimen was subjected to high-load fatigue loading of $F_{\max }=17,800 \mathrm{~N}(4000 \mathrm{lbf})$ and $F_{\min }=1,780$ $\mathrm{N}$ (400 lbf), i.e., $R=0.1$. The precrack size was $2 a=25 \mathrm{~mm}$; the corresponding stress intensity factor at the beginning of the test was $\Delta K \cong 5.8 \mathrm{MPa} \sqrt{\mathrm{m}}$.

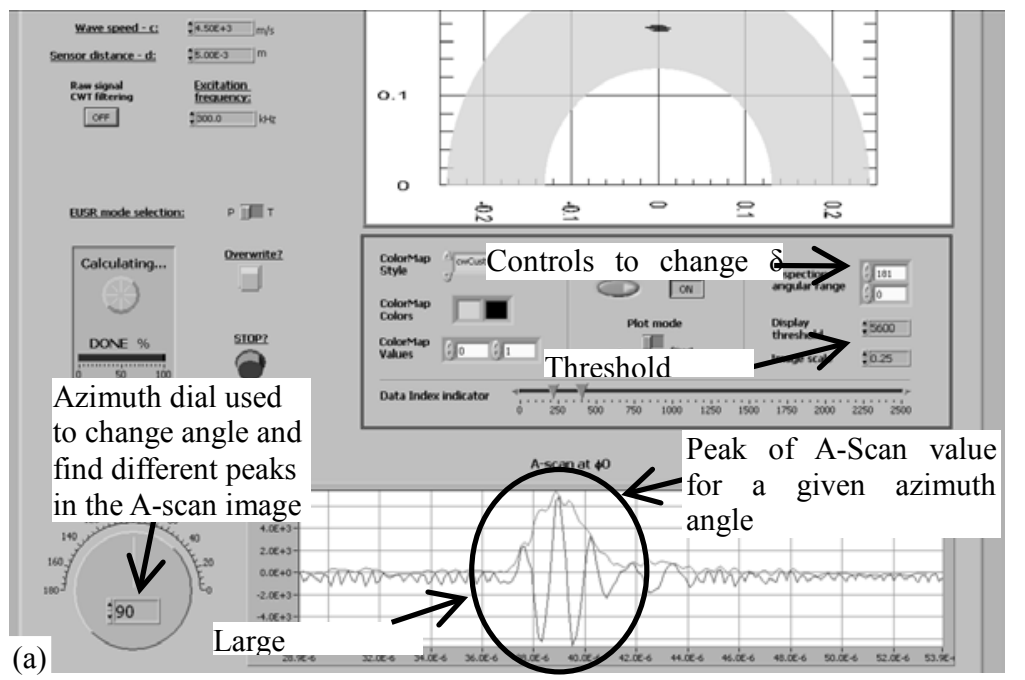

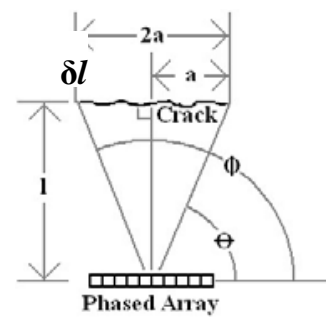

(b)

Figure 3 GUI of the PWAS EUSR program: (a) screen capture shows the angles and threshold controls of EUSR GUI; (b) schematic indicating the $\theta$ and $\delta$ angles in relation to the crack length, $2 a$ and distance to the target [10]

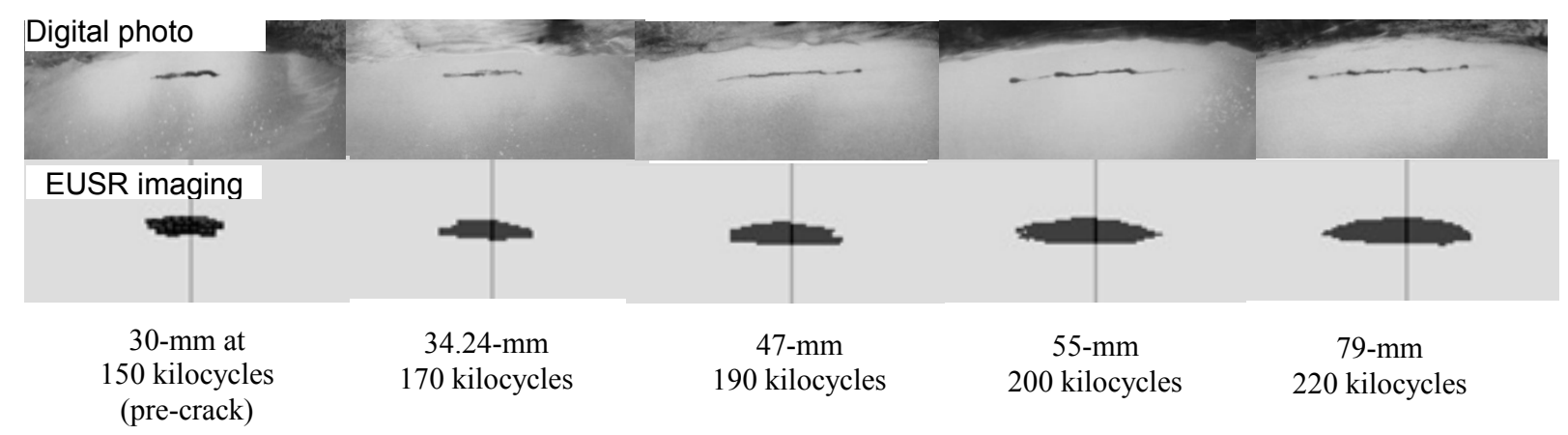

Figure 4 Comparison between optical and EUSR images of cracks during cyclic fatigue test [10] 
During fatigue testing, the crack in the panel grew from $25 \mathrm{~mm}$ to beyond $60 \mathrm{~mm}$. Figure 4 shows a progression of cracks sizes, as they developed in specimen during the fatigue testing. The upper row of the images in Figure 4 displays the optical photos taken with a digital camera. The lower row of images in Figure
4 shows the PWAS phased-array images of the same crack obtained with the EUSR method. Good correspondence exists between the two rows of images in terms crack length versus cycle count.
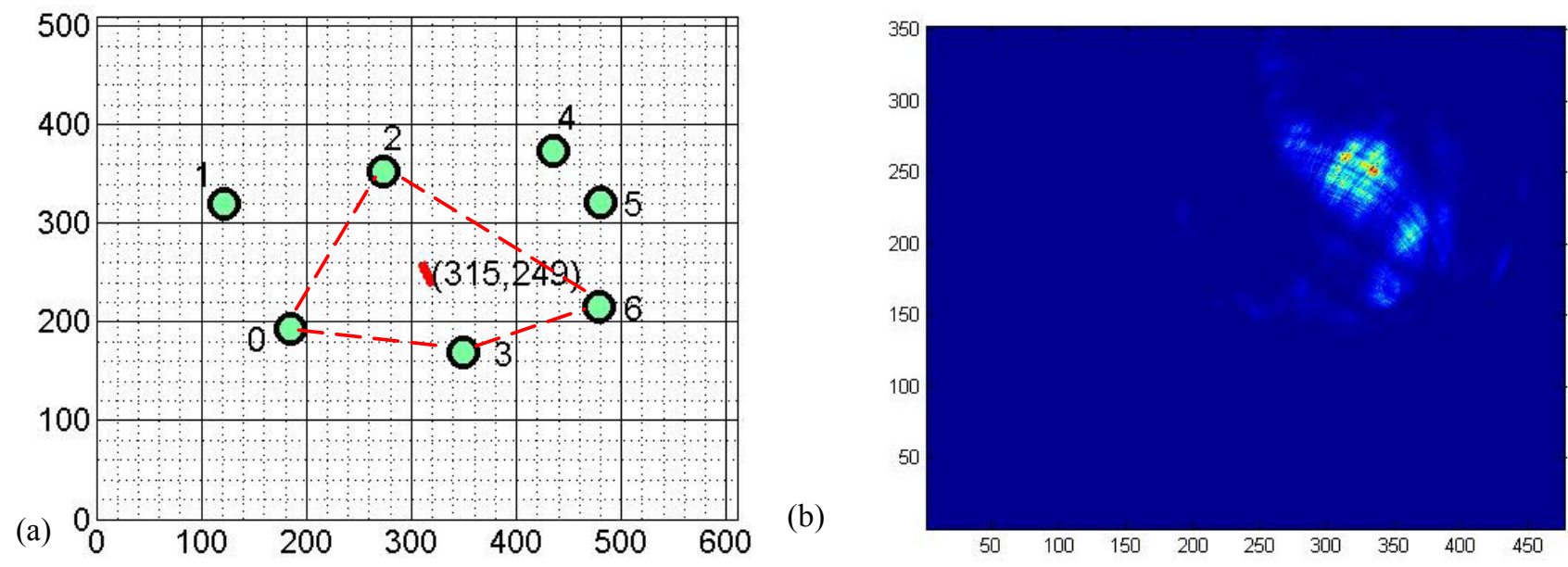

Figure 5 PWAS focusing array imaging for the damage inside the PWAS sparse array [11]

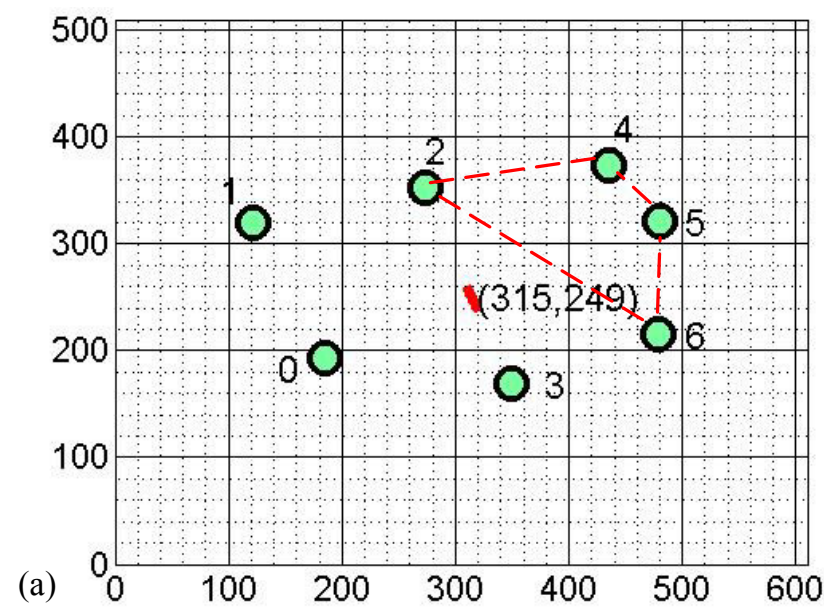

(b)

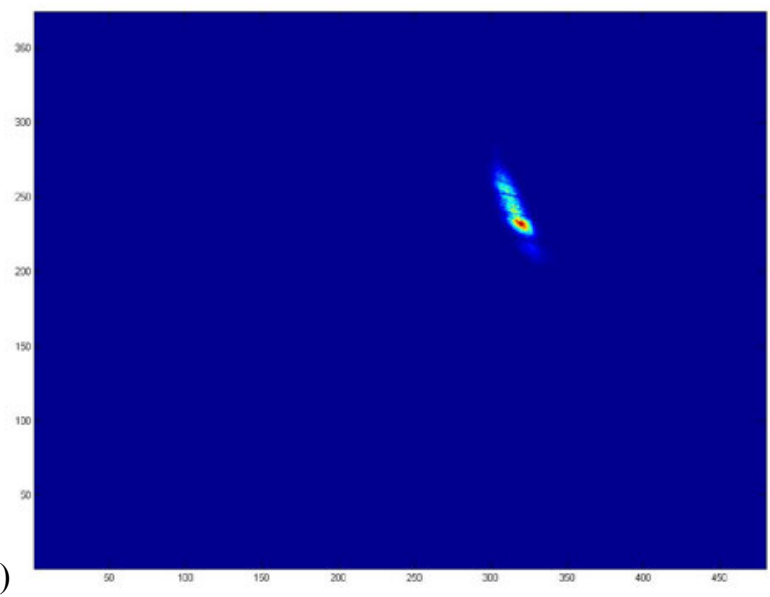

Figure 6 PWAS focusing array imaging for the damage outside the PWAS sparse array [11]

\section{CRACK DETECTION WITH SPARSE PWAS ARRAY IMAGING}

Unlike phased arrays where sensors are physically close to each other, sparse arrays consist of a network of PWAS transducers spatially distributed (Figure 5). Sparse PWAS arrays can also be used to detect damage during the SHM process using an imaging algorithm [11]. The imaging algorithms relies on a guided-wave tomography concept: wave signals transmitted between all the PWAS transducers in the sparse array are scattered by the damage; the scatter effect modifies the signal waveform in comparison with a baseline waveform corresponding to a pristine condition of the structure. The wave scatter is extracted from the signal through the subtraction of previously stored baseline signal. A tomographic data fusion algorithm is applied to the scatter signals to create an image of the damage on the plate. Two situations may arise during damage detection with sparse PWAS arrays: (a) the damage is inside the sensors network; and (b) the damage is outside the sensors network. These situations are depicted in Figure 5a and Figure 6a, respectively.

The sparse PWAS array concept was used to detect a 23mm simulated crack in a $1-\mathrm{mm}$ thick 2024-T3 aluminum plate. 
The crack was placed at location $x=315 \mathrm{~mm}, y=249 \mathrm{~mm}$. A sparse array of seven PWAS was installed on the plate as depicted in in Figure 5a and Figure 6a. A tone burst of the Lamb wave S0 mode tuned at $310 \mathrm{kHz}$ was used as the interrogation signal. Detection of damage inside the sensor array was conducted first: only the PWAS transducers number $0,2,3,6$ were used to form the array (Figure 5a). The resulted image is shown in Figure 6b. It is seen that the two tips of the crack forms two strong scatters of the Lamb wave and generated two strong intensified spots on the images. With estimation of crack tips at $(309,255)$ and $(328,243)$, we can easily estimate the size of the crack at $22.5 \mathrm{~mm}$ with an error of approximately $2.3 \%$.

Figure 6 presents the case when the damage is NOT inside the sparse array, i.e., when transducers number 2, 4, 5, 6 were used to form the array. It is apparent from Figure 6a that the crack is placed outside the sparse array. Imaging results are given in Figure 6b indicating clear and correct location of the 23-mm simulated crack even though it location was outside the sparse array. However, the size of the crack could not be easily determined in this situation when the damage was outside the sparse array. It is apparent from these results that the sparse array method may provide good damage detection and quantification. The limitation of the method is the need for a baseline reading, which was not necessary in the case of the phased-array scanning beam approach.

\section{Current status of SHM usage}

SHM has been intensively investigated by various research groups. An overview of the state of the art of PWAS SHM technology was given in ref. [3], [8]. SHM have been investigated for the aerospace industry including National Aeronautics and Space Administration (NASA), civilian transportation, DOD, DOE, etc.. The place of SHM in the flight structures fundamental research trends and directions was discussed in ref. [12]. The use of the electromechanical impedance technique [13] for SHM of engineering structures has been reviewed in ref. [14]. Vibration based SHM was reviewed in ref. [6], [15]. The connection between SHM and NDE was highlighted in ref.[16]. A comprehensive review of guided-wave SHM was presented in ref. [17]. A conceptual description of combining vibration and wave propagation SHM methods was discussed in ref. [18]. SHM technology has also been applied to civil engineering structures such as bridges [19][20]. Other civil engineering uses of SHM include monitoring of disbond detection in concrete structures strengthened with FRP composite overlays [21], vibration based detection of a fluid filled tank [22]. Active SHM finds is usefulness in green energy systems such as wind farms [23]

\section{POTENTIAL APPLICATION OF SHM CONCEPTS AND METHODS TO RWSS}

A key aspects to improving the reliability, sustaining the safety, and extending the life of current LWR's and associated RWSS is to develop technologies and other solutions that can better diagnose the health of nuclear related systems and structures such as RWSS [24][25][26]. NRC 10 CFR 72.122(h)(4) [27] states that "Storage confinement systems must have the capability for continuous monitoring in a manner such that the licensee will be able to determine when corrective action needs to be taken to maintain safe storage conditions. For dry used fuel storage, periodic monitoring is sufficient." Regulatory Position 1.5, "Monitoring of Structures", in NRC RG 1.160, Rev. 2, provides an acceptable basis for satisfying this program element. A structure may be monitored in accordance with 10 CFR 50.65(a)(2) provided there is no significant degradation of the structure. A structure is monitored in accordance with 10 CFR 50.65(a)(1) if the extent of degradation is such that the structure may not meet its design basis or, if allowed to continue uncorrected until the next normally scheduled assessment, may not meet its design basis [28]. SHM concepts can be transitioned from civil engineering structures to RWSS applications. Several active SHM methods using PWAS transducers [8] can be simultaneously considered. For example one can use simultaneously: (a) the electromechanical impedance method and (b) the pitch-catch Lamb wave propagation with phased array and sparse array imaging.

\section{Dry Cask Storage Systems for extended storage of used fuel}

Dry cask storage systems (DCSS) are being employed in the US and around the world as interim solution for the storage of used nuclear fuel. Dry cask storage systems (DCSS) have been deployed in relatively large numbers at US reactor sites over several years. In total, there are over 1482 DCSS in use at US plants storing 57,807 fuel assemblies. Detection and monitoring has been identified by U.S. Department of Energy (DOE) as a high priority cross-cutting need [29]. Monitoring and detection for DCSS have been also highlighted as a high-priority gap area to ensure the safe long-term storage of used nuclear fuel [25]. Monitoring is necessary to determine and predict the degradation state of the systems, structures, and components (SSCs) important to safety (ITS) and is required by regulation [30][31][32]. Revisions to NUREG 1927 [33] suggest requirements for monitoring and inspection of dry storage systems as part of aging management plans.

The development of monitoring technologies for RWSS will need to meet aspects associated with the functionality ITS structures. For example for dry storage systems monitoring sensor power, data transmission, sensor compatibility, and data management need to be considered as part of the implementation. In the case of DCSS the confinement boundaries of dry storage systems are designed to act as a resilient barrier to the exchange of solids, fluids, and radiation. Therefore, maintaining the integrity of this barrier while assessing DCSS internals is inherently difficult.

\section{NPP life extension (aging management)}

Longer term operation (LTO) of NPP will require a better understanding of the fundamental degradation signatures for ITS components as well how these components relate to the "overall health" of the system. The ability to successfully 
manage the passive systems and structures in NPPs is seen as critical to the goal of long term operability [34]. The global fleet of commercial NPP as 2012 includes 437 operating plants and 68 new reactors under construction [35][36][37][38][39]. The US fleet of commercial NPP includes 104 plants [40] of which fourteen have moved into extended operation (past 40 years) with several others currently undergoing review to extend their licenses to 60 years [41][42]. The average age of NPP plants worldwide which started operation with a $30-$ or 40 years licenses is now over 26 years, with many countries considering life extension to their nuclear facilities. The safe operation of these NPP is tied in part to conducting periodic inspection using a variety of NDT methods. The construction, pre-service, and in-service inspection (ISI) programs developed by the fabricators and owners of the nuclear power plant in the US are driven by the requirements in the American Society of Mechanical Engineers boiler and pressure vessel code (ASME code) and the requirements of the US Nuclear Regulatory Commission (NRC).

In order to meet increasing demand for energy, the US nuclear industry is turning to life extension of existing nuclear power plants. Ensuring safe, secure, and reliable longer term operation of aging nuclear power plants presents many challenges. Online monitoring of structural components has been identified by DOE-FCRD and LWR's sustainability workshop as an essential tool for the understanding and management of nuclear related aging structures $[43][44][45][46][47]$. By measuring parameters related to the degradation of structures (i.e. pitting, crack propagation, wall thinning) technique such as SHM can provide a variety of advanced online surveillance and diagnostic tools for continuous monitoring and on-demand assessment of the health of NPP and RWSS components. By moving from traditional NDE to advanced integrated sensors, SHM can be employed to estimate the remaining useful life using prognostic methodologies.

\section{Fukushima (40 years of clean up)}

Off-normal occurrences and natural events such as the loss of coolant accident (LOCA) caused by the Tsunami and earthquake in Japan have underscored the need to have autonomous real time monitoring systems that can assess the condition of structures such as RWSS in a timely manner. Two important areas can be addressed through with SHM based system: (1) The ability to remotely monitor and inspect the structure without the presence of civilian. For example the high radiation levels during and after the Tsunami event made it impossible for civilian to inspect the facilities or use traditional NDE equipment. (2) The ability to remotely inspect hard to reach areas or obstructed areas. This also became essential after the aftermath of the Tsunami events. Among the most pressing issues recently was the leak of highly radioactive water from three of seven underground storage pools into the soil. The contaminated water storage has been a problem since early in the accident. Runoff from the three reactors melted in the aftermath of the March 2011 quake-tsunami and a steady inflow of groundwater seeping into the basement of their damaged buildings produced about 400 tons of contaminated water daily at the plant.

Following the accident at TEPCO's Fukushima Daiichi Nuclear Power Station, the ability to quickly deploy a system to assess the health of the structures, including identification of debris, was also highlighted. SHM based on PWAS structures can be integrated with other technology (i.e. cameras or radiation sensors) and deployed remotely by the use of remote vehicles. Nuclear sensors, remote vehicles, cameras, and software algorithms are proven technologies and can be integrated with SHM. Real time data analysis will aid in the identification of high radiation areas and allow these areas to be quantified and mapped for health assessment. Quickly deployable sensors that can map and assess the health of structures would have been a valuable tool in the aftermath of Fukushima Daiichi nuclear incident.

\section{NPP and RWSS in US (\$40 million per nuclear unit)}

In response to the Fukushima accident in Japan, US agencies such as NRC and international agencies such as the International Atomic Energy Agency (IAEA) have urged nuclear operators to "improve the reliability of essential systems to assess the structural integrity of site facilities and to enhance protection against external hazards". In March 2012, NRC issued orders requiring nuclear plants to document and upgrades their ability to withstand extreme external events, such as earthquakes and floods, and to operate safety and cooling systems after the loss of electric power, known as station blackout. The expected cost per nuclear power plant (NPP) is estimated to be between \$30 million to \$40 million per unit. Opportunities exist to employ predictive technologies which can reduce operation and maintenance cost, and potentially maintains a high capacity factors. Predicting the residual safe life of RWSS components that have exceeded their design life is a challenging task. By measuring and mapping the state of structures (i.e. wall thickness, crack location and crack length) and comparing with historical data of the structures it will be possible to diagnose the health of structures that have exceed their design life. This data can serve to evaluators and regulators to determine the condition for the safe operation of the system. In addition it can provide awareness of the actual health of the system vs. the predicted state.

\section{RWSS and Defense High Level Waste}

Savannah River Site (SRS) HLW tanks have being in service nearly 50 years. Periodic visual and ultrasonic (UT) nondestructive examinations (NDE) have been performed on the tanks to monitor the effects of service. These facilities have hazardous environments including high radiation, chemicals, underwater, or high temperature. These inspections revealed that some of the older tanks had suffered cracking as detected by through-wall visual indications. Inspection program specifies (a) examination of regions of the tank that would be most susceptible to corrosion attack, (b) characterization of the flaws and (c) demonstration of acceptance to protect against 
potential leakage and instability. A summary of the tank features are as follows:

- Construction - 1955 through 1956, Entered high level waste storage service in 1960.

- Capacity - 1,030,000 gallons

- Material - ASTM A285, Grade B Carbon Steel (Not stress relieved)

- Construction Code - ASME-52

- $\quad$ Five 5-foot steel secondary containment pan

The Savannah River Site has successfully integrated sensors and remote vehicles for deployments at various locations. The integration of SHM (e.g., PWAS) as an additional NDT tool can bring additional robustness to existing programs and improve the reliability of essential systems.

\section{Hanford HLW Tank - (\$300 million a year)}

The Hanford high-level waste (HLW) tank, at the US Hanford Site on Washington State has 177 underground storage tanks that hold about 53 million gallons of high-level radioactive and chemical waste, a byproduct of processing nuclear material, a process that began at Hanford on December 1944 and continued throughout the cold war. By 1964, Hanford had 149 tanks in 12 groups of tanks called 'tank farms' (Figure 7). The earliest tanks were 55,000 and 530,000 gallons in size [48]. Newer tanks ranged from 758,000 to one million gallons. The earliest tanks were originally designed to be used for only 1020 years. The earliest tanks were built with a carbon steel lining (tanks were built during World War II, when there was a shortage of stainless steel). The highly acidic environment caused corrosion to the tank and as result thinning in the tanks walls.

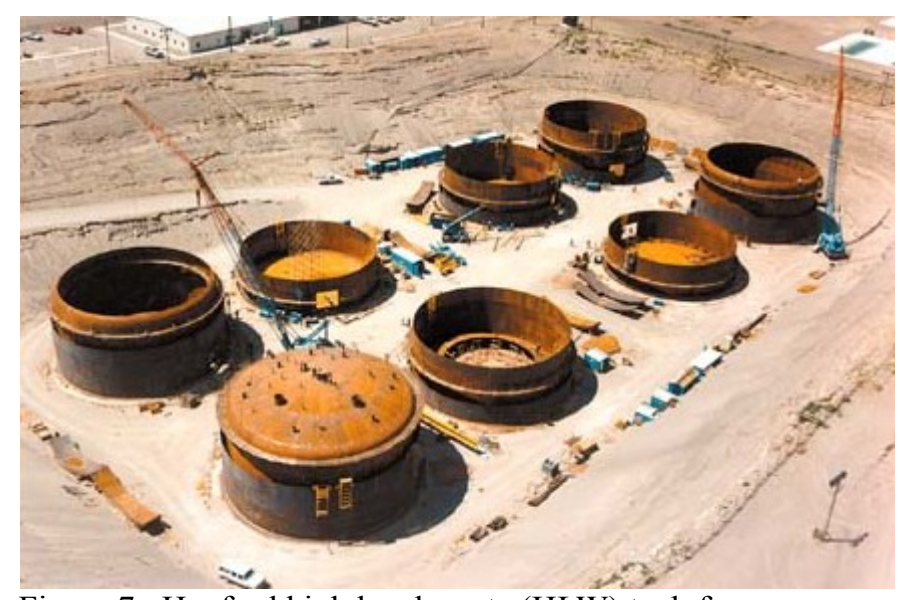

Figure 7 : Hanford high level waste (HLW) tank farms

By the late 1950s, Hanford officials realized that some of the tanks - designed to be used for only 10 to 20 years - had leaked. Eventually, to try and prevent future leaks, tanks with a double shell of steel were built, beginning in the late 1960s. Out of the 177 tanks, at least 67 tanks are suspected of or known to have leaked highly radioactive waste into the soil [49]. Given the weakening of the structure and the aging of the tanks for this RWSS that has exceeded its design life, continuous work is being performed at the at the Hanford site to monitor the conditions within the tanks and, when necessary, to transfer the waste from older single-shell tanks to more modern doubleshell tanks. For continued use, the assessing of the condition of these aging structures (i.e. wall thinning, pitting, crack initiation or crack propagation) is of vital importance. For example, the capability for continuous monitoring of existent cracks and detection of new cracks would provide timely information to managers and engineering to prevent a leak. A continuous health monitoring approach combined with existent NDE tools and historical structure data can potentially aid in the prognosis of the systems and could help to determine the residual safe life of the structure.

\section{NDE and SHM Research Needs and Challenges}

The utilization of SHM for RWSS will require additional research and development as well validation as an alternative nondestructive testing (NDT) and nondestructive evaluation (NDE) tool. As existing RWSS continue to operate, some of them exceeding their designed life span, new degradation processes are being found. For these new degradation processes, the effectiveness of existing inspection and NDE tools is unknown [50]. Many inspections on NPP and RWSS cannot be conducted effectively on a number of materials and configurations. Potential radiation exposure and obstructed areas (i.e., partially buried HLW tanks) also limit the inspectability of such systems. Other conditions found in the field that may limit the inspectability include surface condition in the inner and outer diameters of weldments, access constraints, and tapers that exist on components transitioning from one diameter to another. For these reasons, new ways to assess the in-service state of structures must be found. A potential approach is to use SHM concepts and technologies that have been developed elsewhere but may be quite applicable to RWSS with appropriate modifications.

While the SHM technology has been investigated for other civil applications [19][20][21], there are unique challenges associated to the adaptation of SHM to RWSS. Some of these challenges include:

- Adaptation of SHM technology to existent and new nuclear related structures, including deployment in hard to reach areas.

- Compatibility and resilience of sensors in RWSS applications (i.e. radiation field) and interaction of sensor with the structures during LTO.

- Capability to operate SHM during off normal conditions or accident events.

- Diagnosis and life prediction in aging RWSS structures, where there is no baseline; this may be possible to achieve by integrating inspection historical data from the structure

- Converting sensor data into a reliable prediction tool. For example data will need to be applicable to other fields such as fracture mechanics. This include how to translate SHM data to a physical meaning, i.e. crack length, crack configuration, depth, and the load on the crack. 
- Implementation and acceptance of SHM under existent codes and regulations. For example ASME codes are based upon fatigue, but several other degradation processes that are susceptible to material failure ("failure criteria") need to be consider for diagnosis and prognosis.

- Validation of SHM methods to predict the remaining life of the structures

- Transition from diagnostic methods to prognostic methods

Inherent challenges of online and remotely operated monitoring tools such as the transmission, collections, and management of data are also applicable SHM systems. For facilities that have exceed their design life, the evaluation of new degradation processes and degradation precursors that may be encounter during LTO will need to be addressed. In addition as new methods for detection and quantification of degradation are employed, how to integrate them with existent aging management program has to be further considered. For systems that have exceeded their design life but are still in operation challenges include how to establish a baseline measurement and how to determine the remaining service life. Prolonged exposure to radiation environment is another area that needs to be further evaluated. For example prolonged exposure of electronics to nuclear radiation can introduce measurement artifacts as well as significant damage to sensors and electronic equipment. Turning SHM data into a reliable prediction tool for NPP and RWSS application is another challenge of existing SHM systems. Overcoming such limitations is a major research need in this area.

\section{Obstructed areas}

While several technologies have been developed for the inservice-inspection there is a need to improved monitoring of obstructed areas. The integration of sensor technology such as damage image array based on PWAS can provide vital information by deploying sensors in strategic locations outside the obstructed areas it will be possible to image hard to reach areas. By applying "sensor network" or "sensor array" it will be possible to evaluate and quantify structural defects in RWSS, particularly, in inaccessible locations. Two implementations of this concept are possible: (a) the phased array, and (b) the sparse array.

\section{Sensor compatibility}

The harsh environment associated with RWSS will challenge the use of many types of sensors due to high temperature and/or gamma radiation stressors. For applications to DCSS the development of appropriate sensors that can tolerate initial cask loading temperatures and radiation levels with minimal functional degradation is necessary. This can be addressed through either the design or modification of materials to increase resistance to the effects of radiation and temperature or developing new materials or sensing schemes. The LAMSS team at USC has begun testing PWAS systems under radiation field [51]: Durability and survivability of PWAS transducers were tested under gamma ray exposure. A Co-60 gamma source was used to irradiate a set of PWAS transducers in an irradiator with different exposure times. The dose rate and total absorbed dose were calculated using Monte Carlo simulations (MCNPX code). The PWAS material properties, electrical contact change were characterized through a series of tests. The electromechanical impedance spectrum of PWAS was measured. This study provides a first step towards the fundamental understanding of the PWAS irradiation survivability. Another outcome of this study is to evaluate the potential of PWAS transducers as irradiation sensors for nuclear applications.

\section{SUMMARY AND CONCLUSIONS}

The projected worldwide increase in energy consumption accompanied by a decrease in fossil fuel sources will likely necessitate the move to extend the service life of the global fleet of aging commercial NPP. The same demand will be place on RWSS systems that has exceeded their design life. Presently, the safe operation of NPP and RWSS has been tied in part to conducting periodic inspection using a variety of NDT methods that have shown to be inadequate or difficult in many situations, such as in the presence of radiation field and in obstructed areas.

SHM is a multidisciplinary process that involves several disciplines that must be closely coordinated. Sensors are being used to measure parameters such as temperature, pressure, radiation levels, $\mathrm{pH}$, and wall thickness or to indicate that damage or failure in a system has already occurred (i.e. detection of a leak). But through the implementation of SHM approach the detection of materials degradation at relatively early stages, before the damage occurs, can be potentially achieved.

Therefore, the development of active and passive nondestructive evaluation methods based on SHM provides an opportunity to progress the capability of monitoring RWSS. The integration of SHM with existent NDE tool can increase the confidence of the safe operation and provide assurance of the reliability of RWSS during LTO. Moreover, the development of SHM technologies can minimize human intervention, decrease the cost associated with NPP operation, and improve the reliability of essential systems by continuously assessing the structural integrity of nuclear related facilities. While SHM have been employed in different fields, its applicability for RWSS structures will require further development and evaluation. This will required research to address some of the challenges that were discussed. SHM monitoring can provide decision makers, regulatory agencies, and RWSS operators with timely information on the health of the system. Ultimately, this information will result in the reduction of operation and maintenance cost, and the timely response can protect civilian population from catastrophic system failure.

\section{REFERENCES}

[1] NRC Order Modifying Licenses with regard to Reliable Spent Fuel Pool Instrumentation, accessed April, 2013 http://pbadupws.nrc.gov/docs/ML1203/ML12039A148.pdf, 
[2] *** "IAEA report on Reactor and Spent Fuel Safety in the Light of the Accident at the Fukushima Daiichi Nuclear Power Plant", International Experts Meeting, Vienna, 19-22 March 2012

[3] Giurgiutiu, V. (2010) "Piezoelectric Wafer Active Sensors for Structural Health Monitoring - State of the Art and Future Directions", PVP2010 ASME Pressure Vessels \& Piping Division Conference, July 18-22, 2010, Bellevue, WA, paper \#PVP2010-25292

[4] Chang, F-K (1998) "SMART layer - Built-in diagnostics for composite structures," 4th European Conference on Smart Structures and Materials, UK, 1998, pp. 777-781.

[5] Lin, X; Yuan, F G (2001) "Diagnostic Lamb Waves in an Integrated Piezoelectric Sensor/Actuator Plate: Analytical and Experimental Studies", Smart Materials and Structures, 10, 907-913, Nov. 20012001

[6] Liu, L; Yuan, F G (2008) "Wireless sensors with dualcontroller architecture for active diagnosis in structural health monitoring", Smart Materials and Structures, 17(2), 025016, 2008, doi: 10.1088/0964-1726/17/2/025016

[7] Giurgiutiu, V.; Zagrai, A. N.; Bao, J. (2002) "Piezoelectric Wafer Embedded Active Sensors for Aging Aircraft Structural Health Monitoring", Structural Health Monitoring - an International Journal, Vol. 1, No. 1, pp. 41-6, July 2002, Sage Pub.

[8] Giurgiutiu, V. (2008) Structural Health Monitoring with Piezoelectric Wafer Active Sensors, Elsevier Academic Press, 760 pages, ISBN 978-0120887606, 2008

[9] Giurgiutiu, V; Bao, J (2004) "Embedded-ultrasonics structural radar for in situ structural health monitoring of thinwall structures", Structural Health Monitoring-an International Journal, Vol. 3, No. 2, pp. 121-140, Jun 2004, doi: Doi 10.1177/1475921704042697

[10] Giurgiutiu, V; Yu, L Y; Kendall, J R; Jenkins, C (2007) "In Situ Imaging of Crack Growth with Piezoelectric-Wafer Active Sensors", AIAA Journal, Vol. 45, No. 11, pp. 27582769, Nov 2007, doi: Doi 10.2514/1-30798

[11] Yu, L.; Giurgiutiu, V (2012) "Piezoelectric Wafer Active Sensors in Lamb Wave Based Structural Health Monitoring", Journal of Materials, Springer, Vol. 64, No. 7, pp. 814-822

[12] Giurgiutiu, V (2009) "Flight structures fundamental research trends and directions", Aeronautical Journal, 113(1144), 331337, June 2009

[13] Giurgiutiu, V; Zagrai, A (2005) "Damage detection in thin plates and aerospace structures with the electro-mechanical impedance method", Structural Health Monitoring - an International Journal, 4(2), 99-118, Jun 2005, doi: Doi $10.1177 / 1475921705049752$

[14] Annamdas, V G M; Soh, C K (2010) "Application of Electromechanical Impedance Technique for Engineering Structures: Review and Future Issues", Journal of Intelligent Material Systems and Structures, 21(1), 41-59, 2010, doi: 10.1177/1045389x09352816

[15] Fan, W; Qiao, P (2011) "Vibration-based Damage Identification Methods: A Review and Comparative Study", Structural Health Monitoring - an International Journal, 10(1), 83-111, Jan 2011, doi: 10.1177/1475921710365419

[16] Giurgiutiu, V; Cuc, A (2005) "Embedded Nondestructive Evaluation for Structural Health Monitoring, Damage Detection, and Failure Prevention", Shock and Vibration Digest, 37(2), 83-105, March 2005
[17] Raghavan, A; Cesnik, C E S (2007) "Review of Guided-wave Structural Health Monitoring", Shock and Vibration Digest, 39(2), 91-114, 2007, doi: 10.1177/0583102406075428

[18] Mal, A; Ricci, F; Banerjee, S; Shih, F (2005) "A Conceptual Structural Health Monitoring System based on Vibration and Wave Propagation", Structural Health Monitoring - an International Journal, 4(3), 283-293, September 2005

[19] Yu, L.; Momeni, S.; Godinez, V.; Giurgiutiu, V.; Ziehl, P.; $\mathrm{Yu}$, J. (2012) "Dual Mode Sensing with Low-Profile Piezoelectric Thin Wafer Sensors for Steel Bridge Crack Detection and Diagnosis", Advances in Civil Engineering, Vol. 2012, Article ID 402179, 2012, doi:10.1155/2012/402179

[20] V. Godínez, V.; Pollock, A.; Gonzalez, M.; Momeni, S.; Gostautas, R.; Fustos, R.; Newlin, B.; Inman, D.; Farmer, J.; Priya, S.; Ziehl, P.; Caicedo, J.; Zarate, B.; Yu, L.; Giurgiutiu, V.; Nanni, A. (2011) "Self Powered Wireless Sensor Network for Structural Bridge Health Prognosis: Achievements in the First Two Years", 8th International Workshop on Structural Health Monitoring IWSHM 2011, 13-15 Sept. 2011, Stanford University, CA

[21] Giurgiutiu, V; Harries, K; Petrou, M; Bost, J; Quattlebaum, J B (2003) "Disbond Detection with Piezoelectric Wafer Active Sensors in RC Structures Strengthened with FRP Composite Overlays", Earthquake Engineering and Engineering Vibration, 2(2), 213-224, Dec 2003

[22] Zhou, W; Wu, Z; Mevel, L (2010) "Vibration-based Damage Detection to the Composite Tank Filled with Fluid", Structural Health Monitoring - an International Journal, 9(5), 433-445, Sep 2010, doi: 10.1177/1475921710361329

[23] Frankenstein, B.; Fischer, D.; Weihnacht, B.; Rieske, R. (2012) "Lightning Safe Rotor Blade Monitoring Using an Optical Power Supply for Ultrasonic Techniques", $6^{\text {th }}$ European Workshop on Structural Health Monitoring, 3-6 July 2012, Dresden, Germany.

[24] DOE-NE, Light Water Reactor Sustainability Nondestructive Evaluation for Concrete Research and Development Roadmap, http://energy.gov/ne/downloads/light-waterreactor-sustainability-nondestructive-evaluation-concrete

[25] Hanson, B. (2011) Fuel Cycle Technologies Gap Analysis to Support Extended Storage of Used Nuclear Fuel Lab Lead for R\&D Investigations, Storage and Transportation, Presented to the Nuclear Waste Technical Review Board Fall 2011 Board Meeting Salt Lake City, Utah September 13, 2011

[26] US Nuclear Waste Review Board (USNWRB), DOE Plans for Research and Development related to Used-Fuel Disposition, September 13-14, 2011 Fall 2011 Board Meeting, Salt Lake City, UT

[27] NRC Regulations (10 CFR) §72.122 Overall Requirement, http://www.nrc.gov/reading-rm/doccollections/cfr/part072/part072-0122.html (accessed June 2013)

[28] Chopra, O.K.; Diercks, D.; Fabian, R.; Ma, D.; Shah, V.; Tam, S-W; Liu, Y.Y. (2012) Managing Aging Effects on Dry Cask Storage Systems for Extended Long-Term Storage and Transportation of Used Fuel, Rev. 0 Prepared for U.S. Department of Energy Used Fuel Disposition Campaign Argonne National Laboratory June 30, 2012 FCRD-USED2012-000119 ANL-12/29

[29] Meyer, R; Pardini, A; Hanson, B; Sorenson, K. "Used fuel disposition campaign, Review of NDE Methods for Detection and Monitoring of Atmospheric SCC in Welded Canisters for 
the Storage of Used Nuclear Fuel", prepared for US DOE, FCRD-UFD-2013-000085, January, 2013

[30] 10 CFR 72.122, Code of Federal Regulations 10, NRC 72.122 Overall Requirements, http://www.nrc.gov/reading$\mathrm{rm} /$ doc-collections/cfr/part072/part072-0122.html,

last accessed April 2013

[31] 10 CFR 72.128 Code of Federal Regulations 10, NRC 72.128 "Criteria for spent fuel, high-level radioactive waste, and other radioactive waste storage and handling", http://www.nrc.gov/reading-rm/doc-

collections/cfr/part072/part072-0128.html

last accessed April 2013

[32] 10 CFR 72 "Licensing requirements for the independent storage of spent nuclear fuel, high-level radioactive waste, and reactor-related greater than class C waste", http://cfr.regstoday.com/10cfr72.aspx

last accessed April 2013

[33] NUREG 1927 "Standard Review Plan for Renewal of Spent Fuel Dry Cask Storage System Licenses and Certificates of Compliance Final Report, March 2011, http://www.nrc.gov/reading-rm/doccollections/nuregs/staff/sr1927/sr1927.pdf last accessed April 2013

[34] Bond, L.; Ramuhalli, P.; Tawfik, M.; Lybeck, N. (2011) "Prognostics and Life Beyond 60 Years for Nuclear Power Plants", IEEE International Conference on Prognostics and Health Management, June 2011

[35] World Nuclear Association, http://www.worldnuclear.org/info/Current-and-Future-Generation/Plans-ForNew-Reactors-Worldwide/, accessed April 2013

[36] International Atomic Energy Agency (IAEA), "Operational \& Long-Term Shutdown Reactors". IAEA. 2013-04-13, http://www.iaea.org/PRIS/WorldStatistics/OperationalReacto rsByCountry.aspx. last accessed April 2013

[37] European Nuclear Society, "Nuclear power plants", http://www.euronuclear.org/info/encyclopedia/n/nuclearpower-plant-world-wide.htm, accessed April 2013

[38] World Nuclear Association, "Nuclear Power Reactors", http://www.world-nuclear.org/info/Nuclear-Fuel-

Cycle/Power-Reactors/Nuclear-Power-Reactors/

last accessed April 2013

[39] Wikipedia, "Nuclear power by country", http://en.wikipedia.org/wiki/Nuclear power by country last accessed April 2013

[40] World Nuclear Association, "Nuclear Power in the USA", http://www.world-nuclear.org/info/Country-

Profiles/Countries-T-Z/USA--Nuclear-Power/ last accessed April 2013

[41] Nuclear Energy Institute, "US Nuclear Power Plants", http://www.nei.org/resourcesandstats/nuclear_statistics/usnuc learpowerplants, last accessed April 2013

[42] US Energy Information Administration, "Annual Energy Review 2011", September 2012, Office of Energy Statistics U.S. Department of Energy, DOE/EIA-0384(2011)

[43] Hallbert, B. P.; Persensky, J. J.; Smidts, C.; Aldemir, T.; Naser, N (2009) "Report from the Light Water Reactor Sustainability Workshop on Advanced Instrumentation, Information, and Control Systems and Human- System Interface Technologies", August 2009 , INL/EXT-09-16631, last accessed 4/2013, http://www.osti.gov/bridge/product.biblio.jsp?osti id=97 $\underline{4785})$
[44] Department of Energy, Light Water Reactor Sustainability (LWRS) Program, http://energy.gov/ne/nuclear-reactortechnologies/light-water-reactor-sustainability-Iwrsprogram last accessed April 2013

[45] DOE-NE "Light Water Reactor Sustainability Program and EPRI Long-Term Operations Program - Joint Research and Development Plan", http://energy.gov/ne/nuclear-reactortechnologies/light-water-reactor-sustainability-Iwrsprogram , last accessed April 2013

[46] Smith-Kevern, R. (2013) Department of Energy Nuclear Energy Program, Light Water Reactor sustainability, http://www.nrc.gov/reading-rm/doccollections/commission/slides/2013/20130422/smithkevern-Iwrs-slides-20130422.pdf accessed April 2013

[47] US NRC, Order modifying licenses with regard to reliable spent fuel pool instrumentation, http://pbadupws.nrc.gov/docs/ML1203/ML12039A148.pdf last accessed April 2013

[48] Oregon Department Of Energy ODOE Nuclear Safety website http://www.oregon.gov/energy/NUCSAF/docs/ )

[49] *** "Hanford Tank Waste Information", EPA document, http://www.epa.gov/radiation/docs/wipp/doeenclosure9 2.pdf accessed June 2013)

[50] Doctor, S.R. (2007), "Nuclear Power Plants NDE Challenges: Past, Present and Future", Review of Quantitative Nondestructive Evaluation, Vol. 26, 2007

[51] Lin, B.; Mendez-Torres, A. E.; Gresil, M.; Giurgiutiu, V. (2012) "Structural Health Monitoring with Piezoelectric Wafer Active Sensors Exposed to Irradiation Effects", ASME 2012 Pressure Vessels and Piping Division Conference, 1519 July 2012, Toronto, Ontario, Canada, paper PVP201278848 